\title{
Solar Harvested RFID Transponder
}

\author{
M L N Vital \\ Department of Electrical and Electronics Engineering \\ $V R$ Siddhartha Engineering College, Vijayawada, India \\ R Giridhar Balakrishna \\ Department of Electrical and Electronics Engineering \\ $V R$ Siddhartha Engineering College, Vijayawada, India \\ P Yogananda Reddy \\ Department of Electrical and Electronics Engineering \\ $V$ R Siddhartha Engineering College, Vijayawada, India
}

\begin{abstract}
This paper presents the design, analysis and manufacture of feasible, reliable and high range proto type of RFID transponder with continuous operability. A prototype of semi-active RFID transponder is developed to detect the range that can be extended via a DC input to allow all of the readers signal power to be reflected via backscatter modulation. The solar harvesting powered transponder which is selected over other energy harvesting technologies as it provides a greater energy density and lower cost. Solar has one major drawback in terms of providing a steady DC voltage from it needed a constant radiation of sunlight. A method of power storage is proposed, and the use of a super capacitor over a rechargeable battery is used because of its longer lifespan due to higher recharge rates. The prototype is verified under a series of experiments in different working conditions using internet of Things (IoT) and proven as a better solution in providing long durability. The paper concludes the use of solar harvesting with super capacitor storage.
\end{abstract}

Keywords- Energy harvesting, internet of things (IoT), RFID, solar energy, super capacitor.

\section{INTRODUCTION}

In recent years, Radio Frequency Identification Technology has moved from obscurity into mainstream applications that help speed the handling of manufactured goods and materials. RFID enables identification from a distance, and unlike earlier bar-code technology, it does so without requiring a line of sight. RFID tags support a larger set of unique IDs than bar codes and can incorporate additional data such as manufacturer, product type, and even measure environmental factors such as temperature. Furthermore, RFID systems can discern many different tags located in the same general area without human assistance. In contrast, consider a supermarket checkout counter, where you must orient each bar-coded item toward a reader before scanning it. So why has it taken over 50 years for this technology to become mainstream? The primary reason is cost.

Radio-frequency identification (RFID) uses electromagnetic fields to automatically identify and track tags attached to objects. The tags contain electronically stored information. Passive tags collect energy from a nearby RFID reader's interrogating radio waves. Active tags have a local power source such as a battery and may operate at hundreds of meters from the RFID reader.

Many types of RFID exist, but at the highest level, we can divide RFID devices into two classes: active and passive. Active tags require a power source-they're either connected to a powered infrastructure or use energy stored in an integrated battery. In the latter case, a tag's lifetime is limited by the stored energy, balanced against the number of read operations the device must undergo. One example of an active tag is the transponder attached to an aircraft that identifies its national origin. Another example is a Lo Jack device attached to a car, which incorporates cellular technology and a GPS to locate the car if stolen. However, batteries make the cost, size, and lifetime of active tags impractical for the retail trade. Passive RFID is of interest because the tags don't require batteries or maintenance. The tags also have an indefinite operational life and are small enough to fit into a practical adhesive label. 
Energy harvesting or scavenging is the process of generating power for low-power electronic devices, from external sources such as solar, thermal, vibration or ambient RF waves. It is mainly used for small, wireless autonomous devices, like those used in wearable electronics, wireless sensor networks.

\section{A. PASSIVE TAG}

A passive tag is an RFID tag that does not contain a battery; the power is supplied by the reader. When radio waves from the reader are encountered by a passive rfid tag, the coiled antenna within the tag forms a magnetic field. The tag draws power from it, energizing the circuits in the tag. The tag then sends the information encoded in the tag's memory.

\section{The major disadvantages of a passive rfid tag are:}

- The tag can be read only at very short distances, typically a few feet at most. This greatly limits the device for certain applications.

- It may not be possible to include sensors that can use electricity for power.

- The tag remains readable for a very long time, even after the product to which the tag is attached has been sold and is no longer being tracked.

The advantages of a passive tag are:

- The tag functions without a battery; these tags have a useful life of twenty years or more.

- The tag is typically much less expensive to manufacture

- The tag is much smaller (some tags are the size of a grain of rice). These tags have almost unlimited applications in consumer goods and other areas.

\section{B. ACTIVE TAG}

An RFID tag is an active tag when it is equipped with a battery that can be used as a partial or complete source of power for the tag's circuitry and antenna. Some active tags contain replaceable batteries for years of use; others are sealed units. (Note that It is also possible to connect the tag to an external power source.)

The major advantages of an active rfid tag are:

- It can be read at distances of one hundred feet or more, greatly improving the utility of the device

- It may have other sensors that can use electricity for power.

\section{The problems and disadvantages of an active RFID tag are}

- The tag cannot function without battery power, which limits the lifetime of the tag.

- The tag is typically more expensive, often costing $\$ 20$ or more each

- The tag is physically larger, which may limit applications.

- The long-term maintenance costs for an active RFID tag can be greater than those of a passive tag if the batteries are replaced.

- Battery outages in an active tag can result in expensive misreads.

\section{Active RFID tags may have all or some of the following features}

- longest communication range of any tag

- the capability to perform independent monitoring and control

- the capability of initiating communications 


\section{COMPONENT DESCRIPTION}

\section{A. RFID chip (EM 4325)}

EM4325 is a Class-3 Generation-2 (Gen2) IC that is compliant with ISO/IEC 18000-63 (Gen2) \& ISO/IEC 18000-64 (TOTAL) as well as EPCTM Class-1 Generation-2. The chip offers an advanced feature set leading to a performance beyond that of standard Gen2 chips and can be either battery powered or beam powered by the RF energy transmitted from a reader. In a battery assisted passive (BAP) configuration, the EM4325 offers superior reading range and reliability compared to purely passive RFID solutions.

EM4325 includes 4096 bits of high speed non-volatile memory (EEPROM) that is organized into 64 pages with 4 words per page. The chip supports either ISO or EPCTM data structures that are compliant with EPC global Tag Data Standards, Version 1.8, and is delivered with a Unique Identifier (UID) to ensure full traceability.

\section{B. SUPER CAPACITOR}
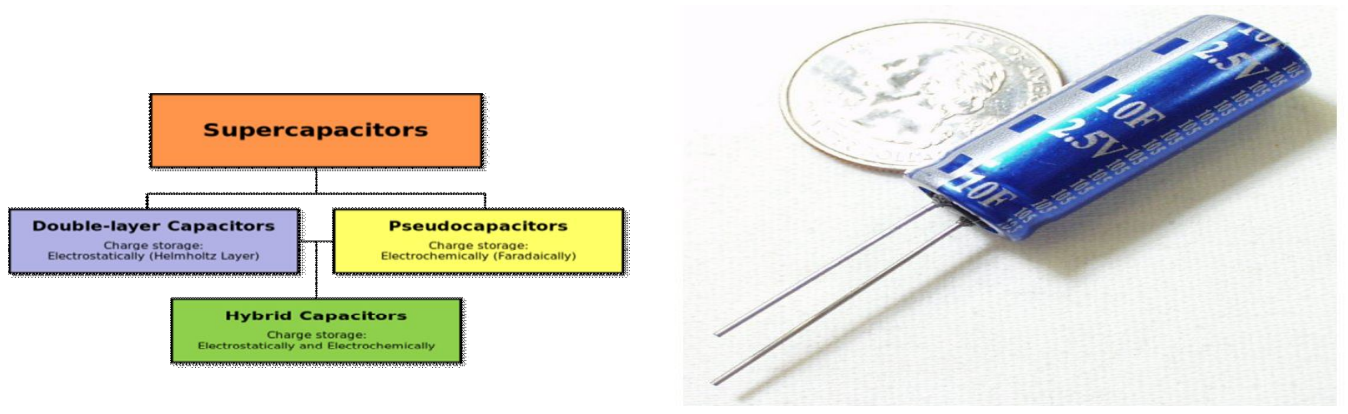

Fig. 1. (a) Super capacitor classification (b) Super capacitor

A supercapacitor (SC) (also electric double-layer capacitor (EDLC), also called super cap, ultracapacitor or Gold cap) is a high-capacity capacitor with capacitance values much higher than other capacitors (but lower voltage limits) that bridge the gap between electrolytic capacitors and rechargeable batteries. They typically store 10 to 100 times more energy per unit volume or mass than electrolytic capacitors, can accept and deliver charge much faster than batteries, and tolerate many more charge and discharge cycles than rechargeable batteries.

Supercapacitors are used in applications requiring many rapid charge/discharge cycles rather than long term compact energy storage: within cars, buses, trains, cranes and elevators, where they are used for regenerative braking, short-term energy storage or burst-mode power delivery. Smaller units are used as memory backup for static random-access memory (SRAM).

Supercapacitors are polarized by design with asymmetric electrodes, or, for symmetric electrodes, by a potential applied during manufacture.

\section{ON BOARD ANTENNA (DIPOLE ANTENNA)}

\section{i. Antenna types}

Antennas can be classified in several ways. One way is the frequency band of operation. Others include physical structure and electrical/electromagnetic design. The antennas commonly used for LMR-both at base stations and mobile units-represent only a very small portion of all the antenna types.

Most simple, non-directional antennas are basic dipoles or monopoles. More complex, directional antennas consist of arrays of elements, such as dipoles, or use one active and several passive elements, as in the Yagi antenna.

\section{ii. Dipoles and Monopoles}

The vertical dipole —or its electromagnetic equivalent, the monopole—could be considered one of the best antennas for LMR applications. It is omnidirectional (in azimuth) and, if it is a half-wavelength long, has a gain of 
1.64 (or $G=2.15 \mathrm{dBi}$ ) in the horizontal plane. A center-fed, vertical dipole is illustrated in figure (a). Although this is a simple antenna, it can be difficult to mount on a mast or vehicle. The ideal vertical monopole is illustrated in figure (b). It is half a dipole placed in half-space, with a perfectly conducting, infinite surface at the boundary.
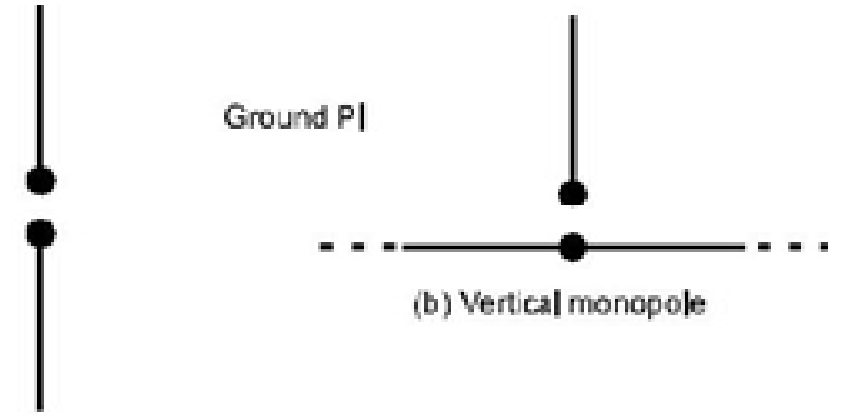

(b) Vertical monopole

(a) Vertical d pole

III. CIRCUIT DESCRIPTION AND OPERATION

\section{A. CIRCUIT OPERATION}

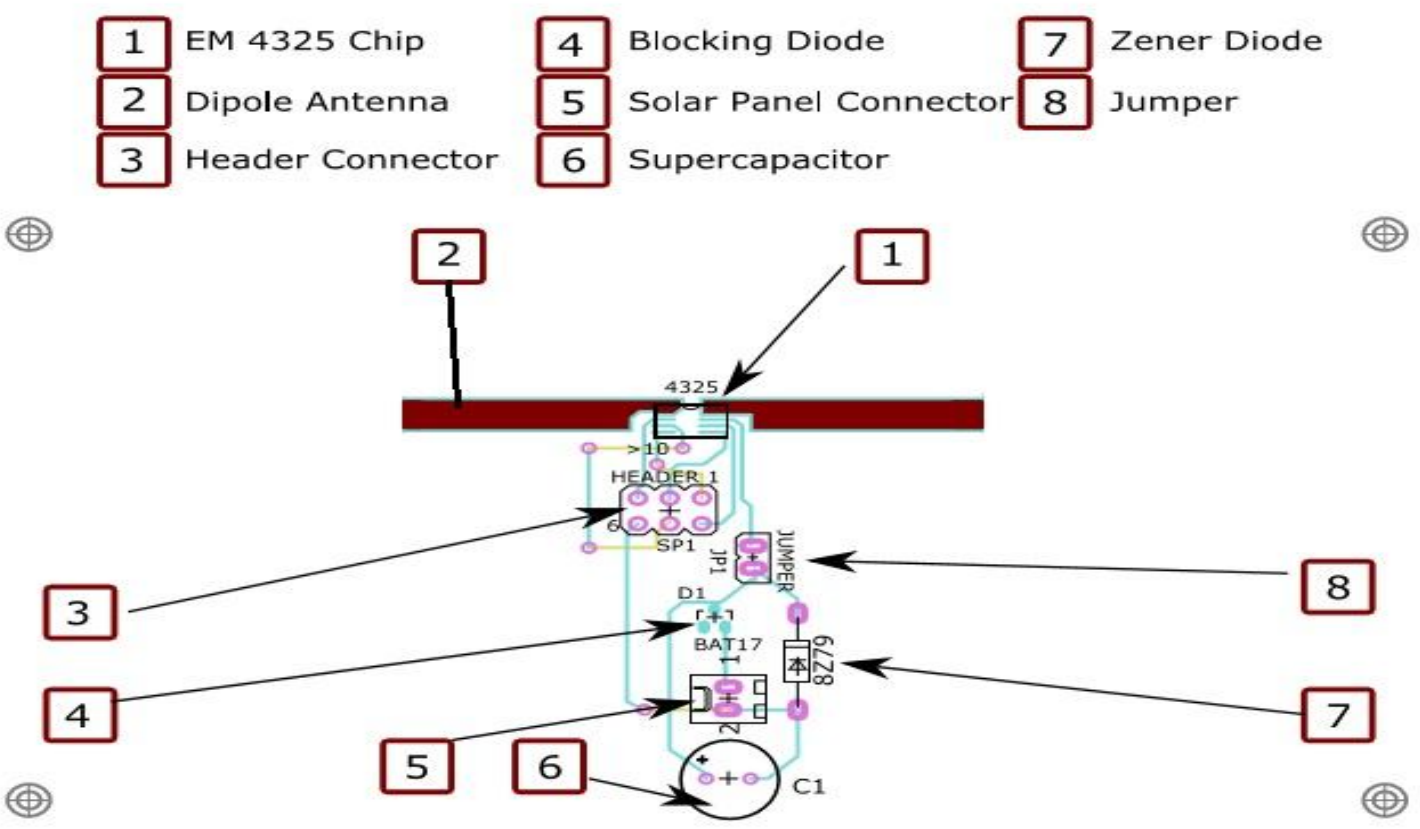

Fig.2. Desired PCB layout

The complete RFID transponder system consists of five separate components, in the block diagram. The RFID Chip requires long range capability and functional operation in the semi-active mode when a DC power source is added. The EM4325 chip is the most suitable as it offers an advanced feature set such as on board temperature sensor with superior reading range and reliability compared to purely passive RFID solutions. The range of battery operating voltage of the EM 4325 is between $1.25 \mathrm{~V}$ and $3.65 \mathrm{~V}$. 


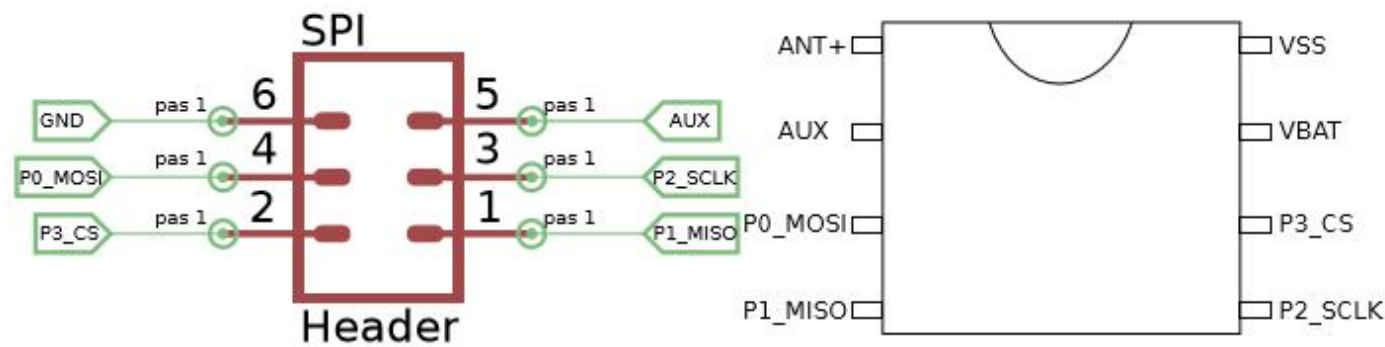

Fig.3. Pin diagram of EM 4325

Figure 3. shows the EM 4325 and the 6 pin header connector. Pins 1 and 8 overlay each side of the antenna while the remaining 6 pins connect with the header connector to allow for the EM 4325 to be programmed via its SPI bus. Pin 7 of the EM 4325 is the VBAT input, which is connected to the supercapacitor via a Jumper that can be removed so the chip can operate without power i.e. in passive mode. The supercapacitor has to be placed as far from the chip as possible to minimize the effect of noise.

\section{REALIZED PROTOTYPE}

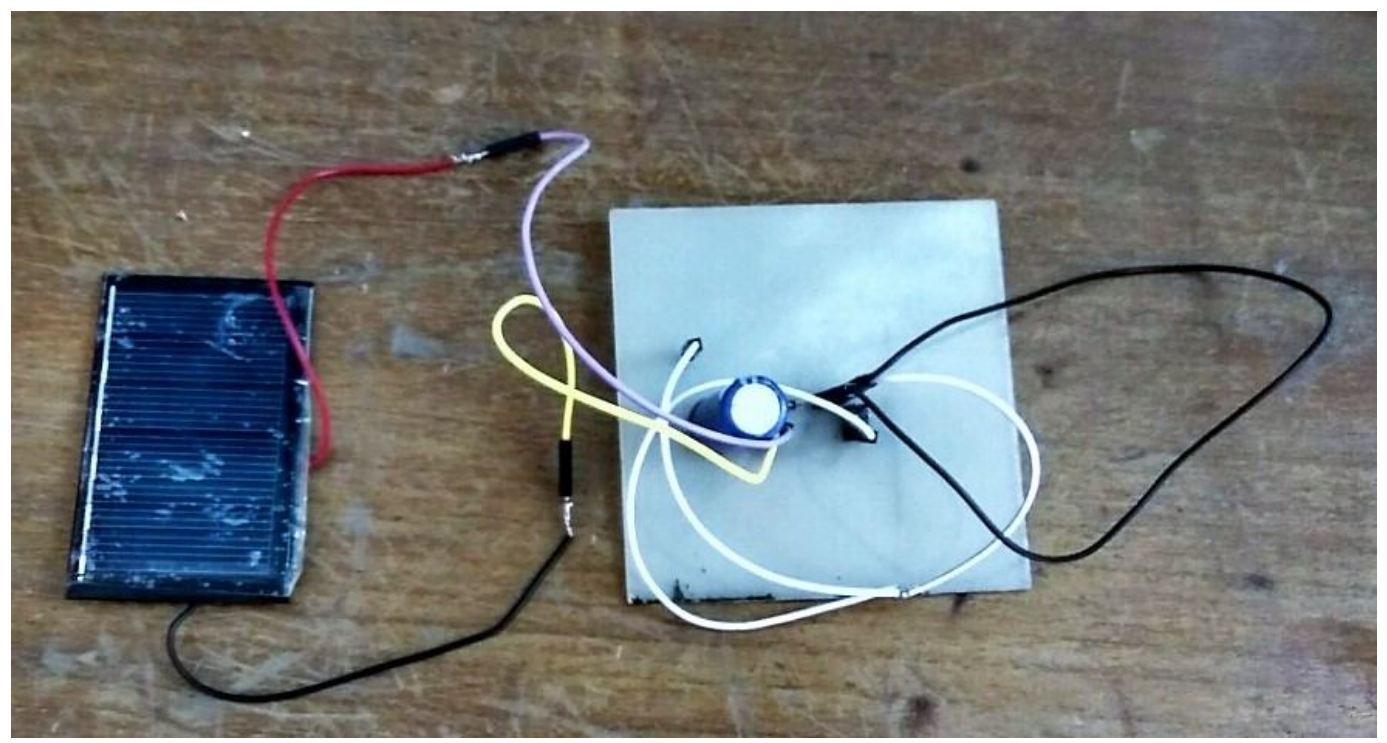




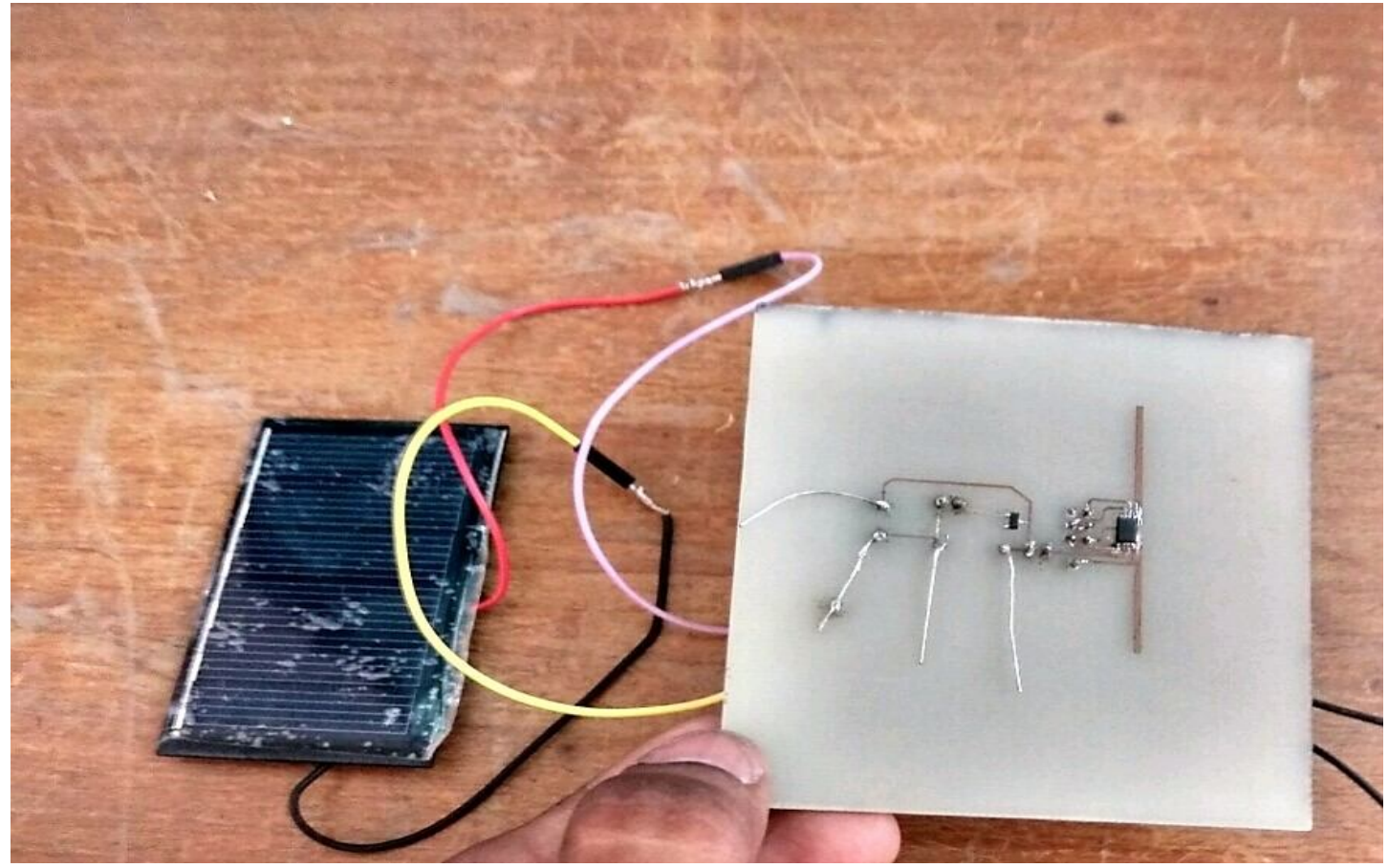

\section{DESIGN CALCULATIONS}

\section{A. DESIGN OF SOLAR PANEL RATING:}

Here RFID chip maximum current and voltage are $3.65 \mathrm{~V}$ and $8.6 \mu \mathrm{A}$

Power consumed by load $=3.65 * 8.6 \mu \mathrm{A}$

$$
=31.39=31.4 \mu \mathrm{W} \text {. }
$$

Now power required by the chip will be supplied by solar panel in daylight of 6 hours.

$$
\begin{aligned}
& =31.4 \mu \mathrm{W} * 6 \text { hours } \\
& =0.2 \mu \mathrm{Wh}
\end{aligned}
$$

Amount of energy required by the chip for the next 3 days without solar input will be stored in super capacitor.

$$
\begin{aligned}
& =31.4 * 3 * 24 \\
& =2.26 \mathrm{mWh}
\end{aligned}
$$

Total energy supplied by panel should be $=\mathbf{2 . 2 6}+0.2$

$$
=2.46 \mathrm{mWh} / 6=0.4 \mathrm{~mW}
$$

Energy stored by capacitor should be equal to $2.26 \mathrm{mWh}$

$$
\begin{aligned}
& 1 / 2 \mathrm{CV}^{\wedge} 2=2.26 \\
& 1 / 2 * \mathrm{C}^{*}(2.5-1.25)^{\wedge} 2=2.26 \mathrm{mWh} \\
& 1 / 2 * \mathrm{C} *(1.25)^{\wedge} 2 *(1 / 3600)=2.26 \mathrm{mWh} \\
& \mathrm{C}=10.4 \mathrm{~F}
\end{aligned}
$$

\section{B. PCB DESIGN USING EAGLE}

In order to design a PCB, you need to complete the following steps: 
- Create a schematic sheet $\&$ add components

- Add nets to the schematic (connect components)

- Check schematic (Electrical Rule Check or ERC)

- Create a board outline

- Position components on the board

- Route tracks between the components

- Check board (Design Rule Check or DRC)

- Pour copper to fill empty spaces on the board

- (Optional) Add text legends to PCB layout

- Perform Final Checks

In EAGLE the schematic design takes most of the time. The PCB layout itself, steps 4-9, uses the excellent built-in auto-router, and can be quick if layout is good, or impossible if layout is bad. If you take time to reposition the components carefully you will reduce the average length of tracks, and get better high-frequency performance from the board, as well as ensuring that even dense layouts can auto-route fully.

\section{SCHEMATIC LAYOUT}

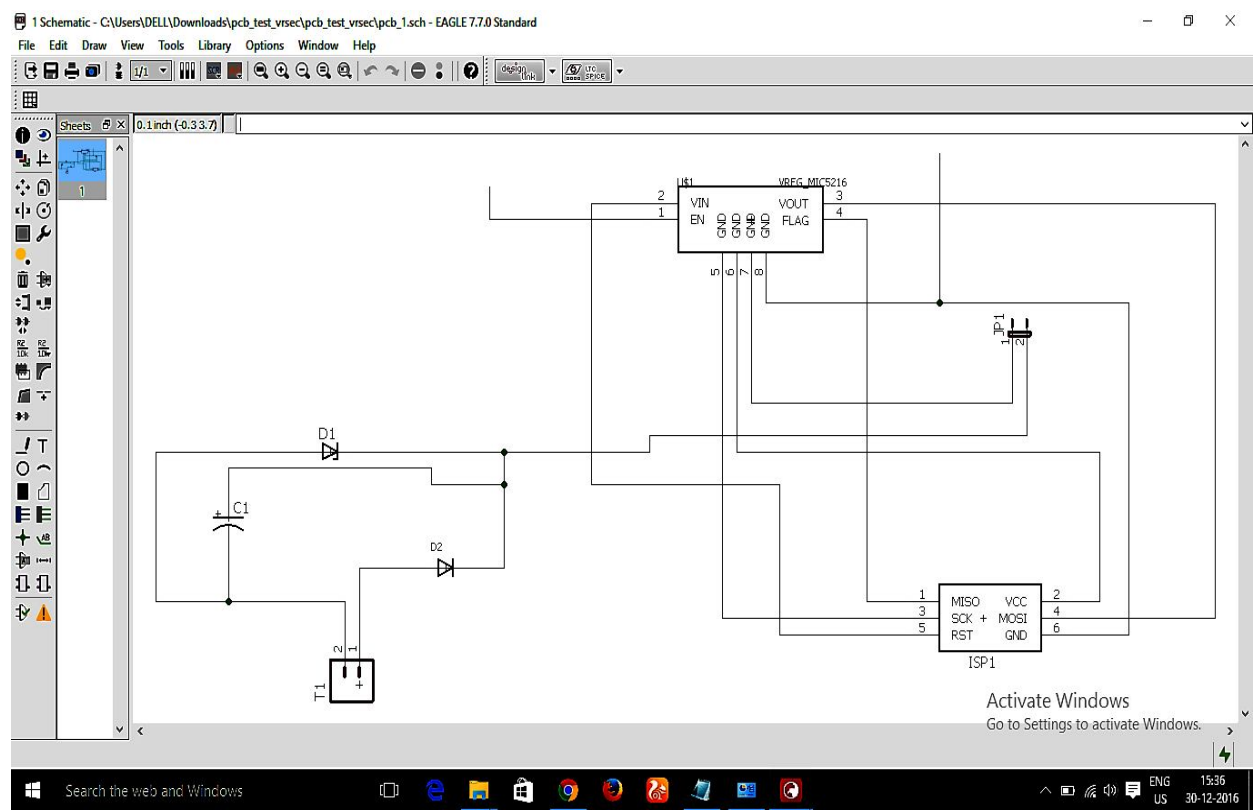

D. BOARD LAYOUT 


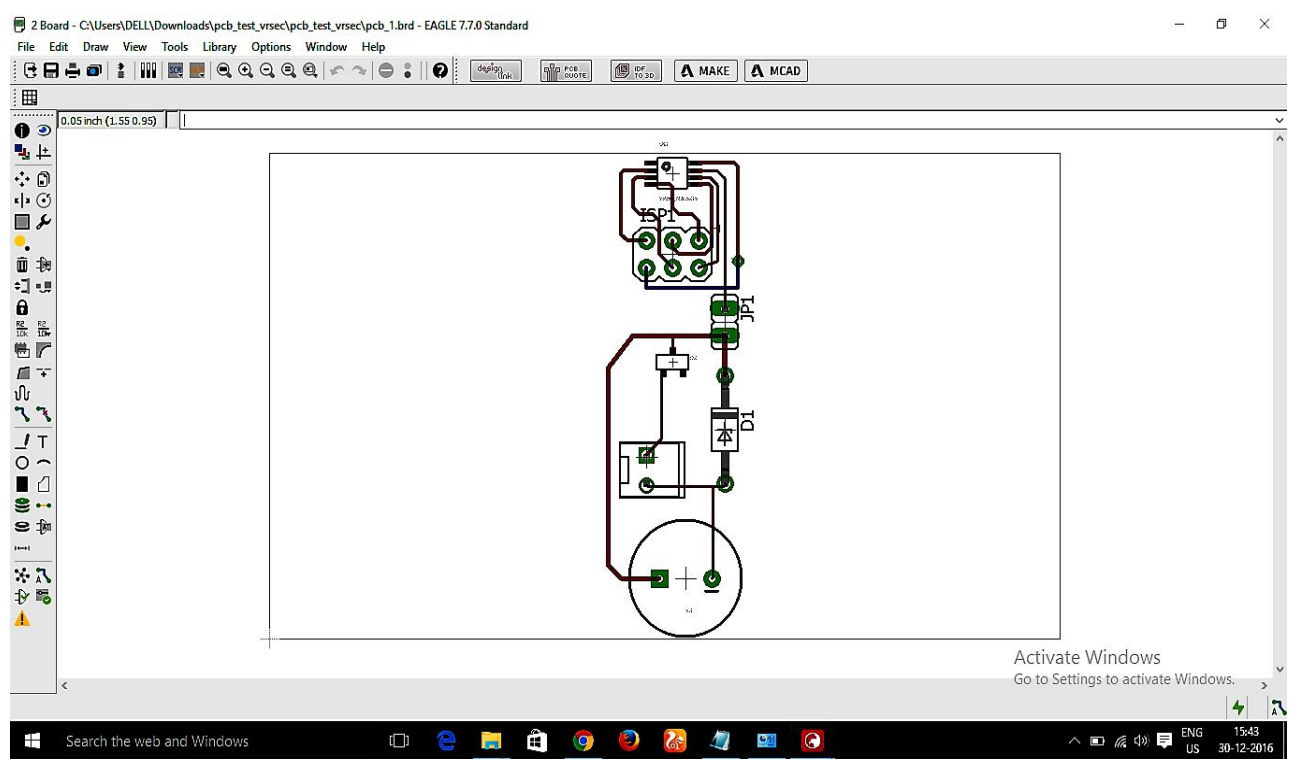

\section{E. DIPOLE ANTENNA DESIGN USING HFSS}

ANSYS HFSS software is the industry-standard simulation tool for 3-D full-wave electromagnetic field simulation and is essential for the design of high-frequency antenna design. You can select the appropriate solver for the type of simulation you are performing. Each HFSS solver is based on a powerful, automated solution process where you are only required to specify geometry, material properties and the desired output. From there HFSS will automatically generate an appropriate, efficient and accurate mesh for solving the problem using the selected solution technology. ANSYS HFSS software contains the technology, solvers and capabilities needed to model RF and microwave as well as signal- and power-integrity issues. Design sign-off accuracy is provided by HFSS through its ground breaking and industry leading adaptive meshing technology. Its powerful meshing and solver technologies allow you to design with confidence, knowing the results provided by HFSS can be relied on. Other tools simply give answers without any feedback regarding the accuracy of the solution, leading to uncertainty.

\section{F. LENGTH OF ANTENNA}

$$
\begin{aligned}
& \lambda=\mathrm{c} / \mathrm{f} \\
& \mathrm{c}=\text { velocity of light }=3^{*}\left(10^{\wedge} 10\right) \mathrm{cm} / \mathrm{s} \\
& \mathrm{f}=\text { frequency }(2.45 \mathrm{GHz})
\end{aligned}
$$

Therefore,

$$
\lambda=61.22 \mathrm{~mm}
$$

Since, for dipole antenna each arm length is $\lambda 2$

$$
\text { Arm } 1=\operatorname{arm} 2=30.61 \mathrm{~mm}
$$

This length is optimized to $44 \mathrm{~mm}$ as we have to resonate antenna at our desired frequency.

\section{G. STEPS TO DESIGN DIPOLE ANTENNA}

- Open HFSS software and create a box with required dimensions (i.e. length breadth, height).

- Assign the desired material i.e. FR4 epoxy substrate, it is preferred because of its low cost.

- Create either arms of dipole antenna by specifying the dimensions.

- Create a feed line between arms $1 \& 2$. 
- Assign perfect $\mathrm{E}$ for both arms which induces copper layer on it.

- Assign lumped port for feed line, whereas lumped port specifies whether the feed line is voltage or current source.

- Create a box and assign vacuum material and assign radiation properties to it.

- Assign resonant frequency i.e. desired frequency of $2.45 \mathrm{GHz}$ in the setup prompt.

- Validate and analyze all.

\section{DESIRED PROPERTIES OF ANTENNA}

- It is need to verify antenna whether it is resonating at desired frequency $(2.45 \mathrm{GHz})$ for which the $\mathrm{S} 1,1$ value must be below -10 .

- Radiation patterns also need to be verified whether they are in desired shapes. The dimensions of the dipole antenna are optimized in order to meet the mentioned results.

\section{RESULTS}

\section{A. OPTIMIZED SIMULATION RESULTS}

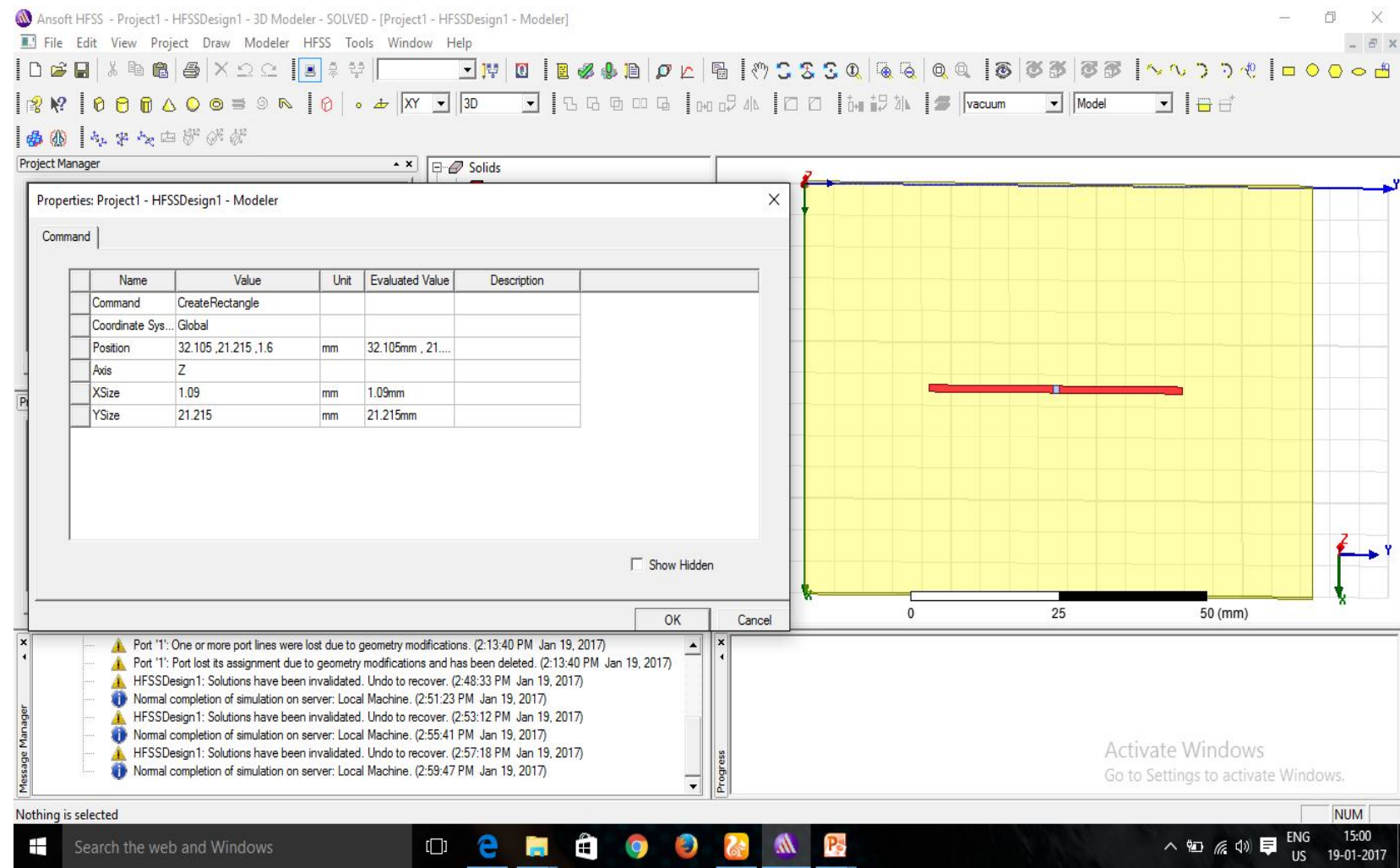

Fig 5.(a) Simulation Results 


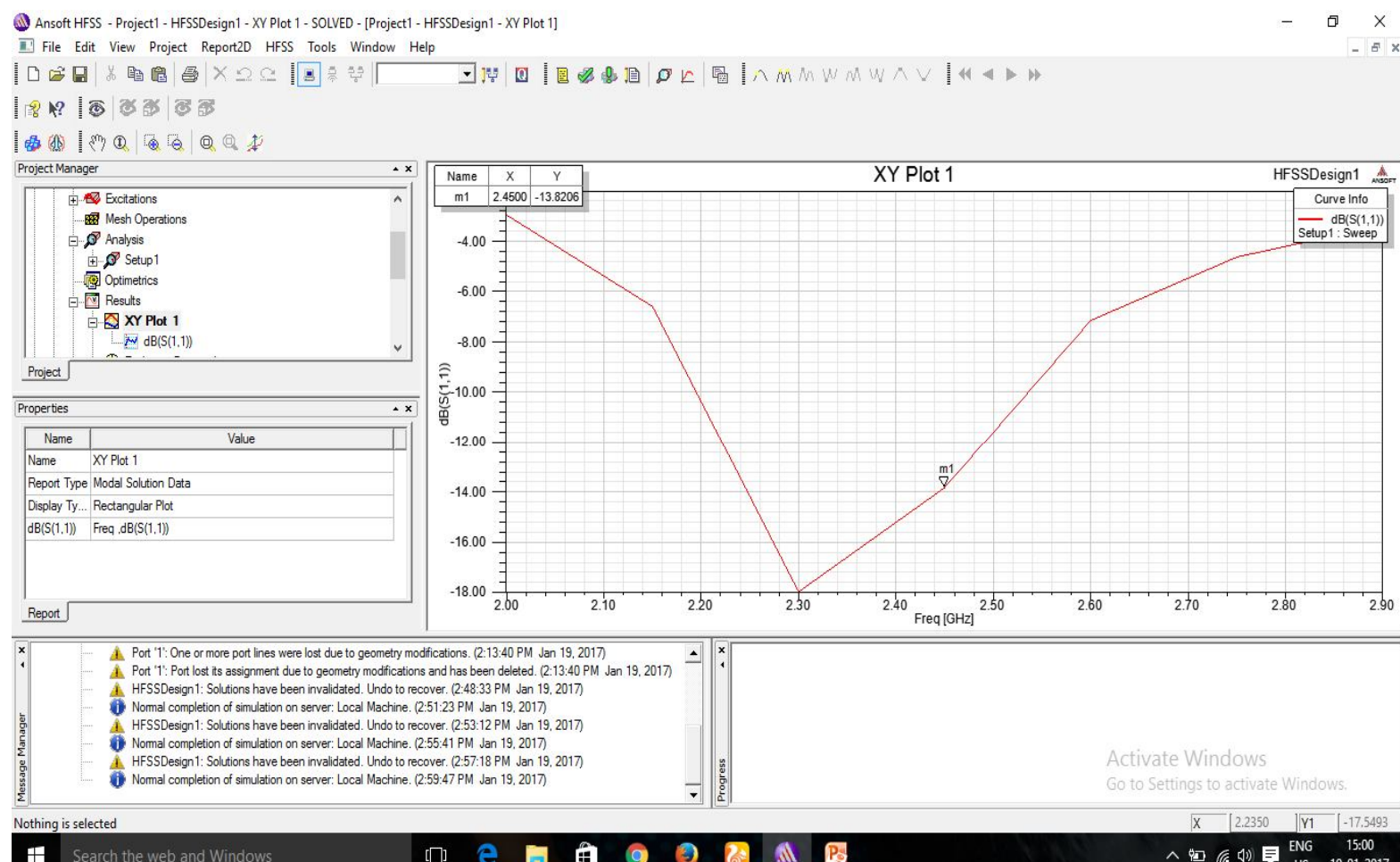

\section{B. PRACTICAL RESULTS}

A. RETURN LOSS PLOT

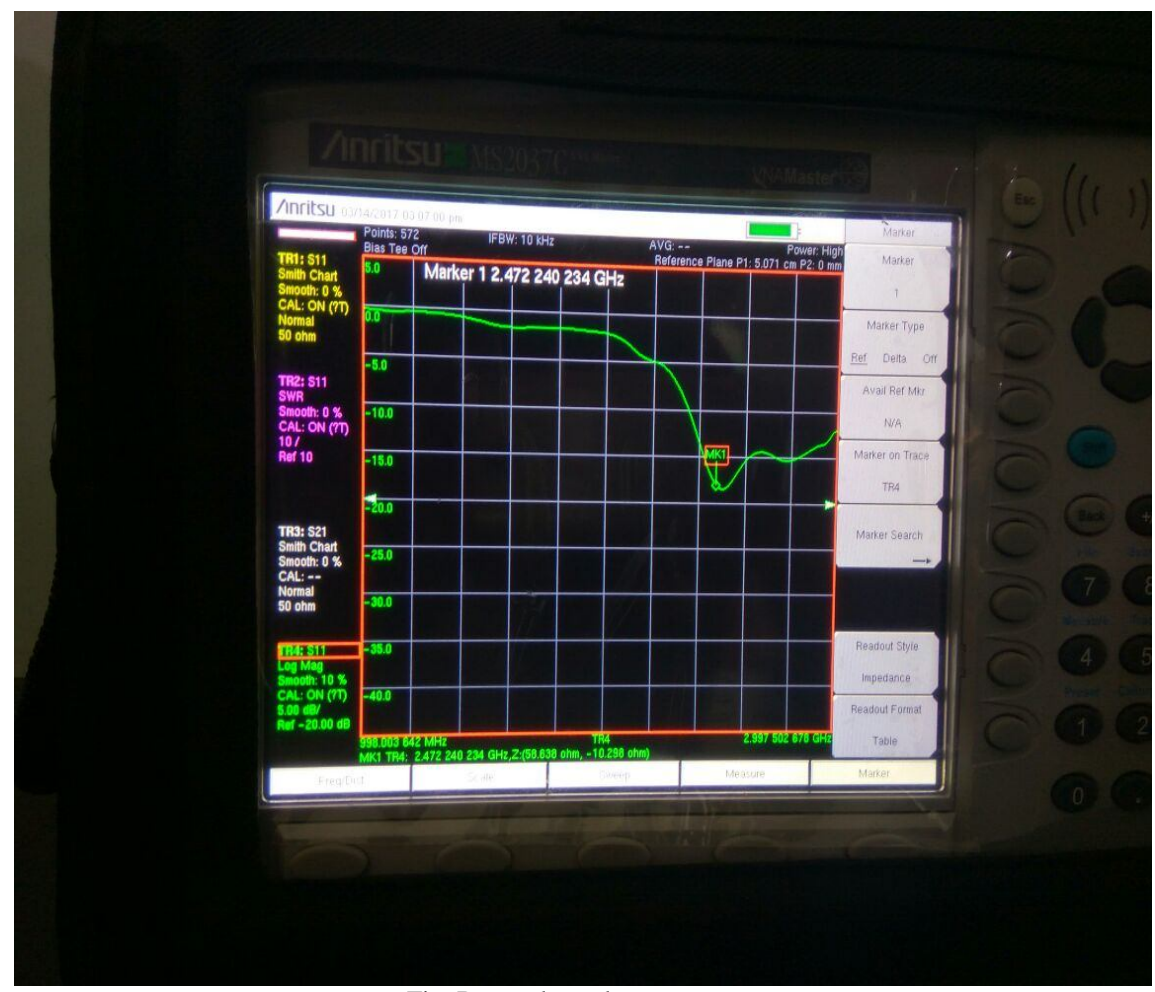

Fig. Return loss plot 


\section{B. VSWR:}

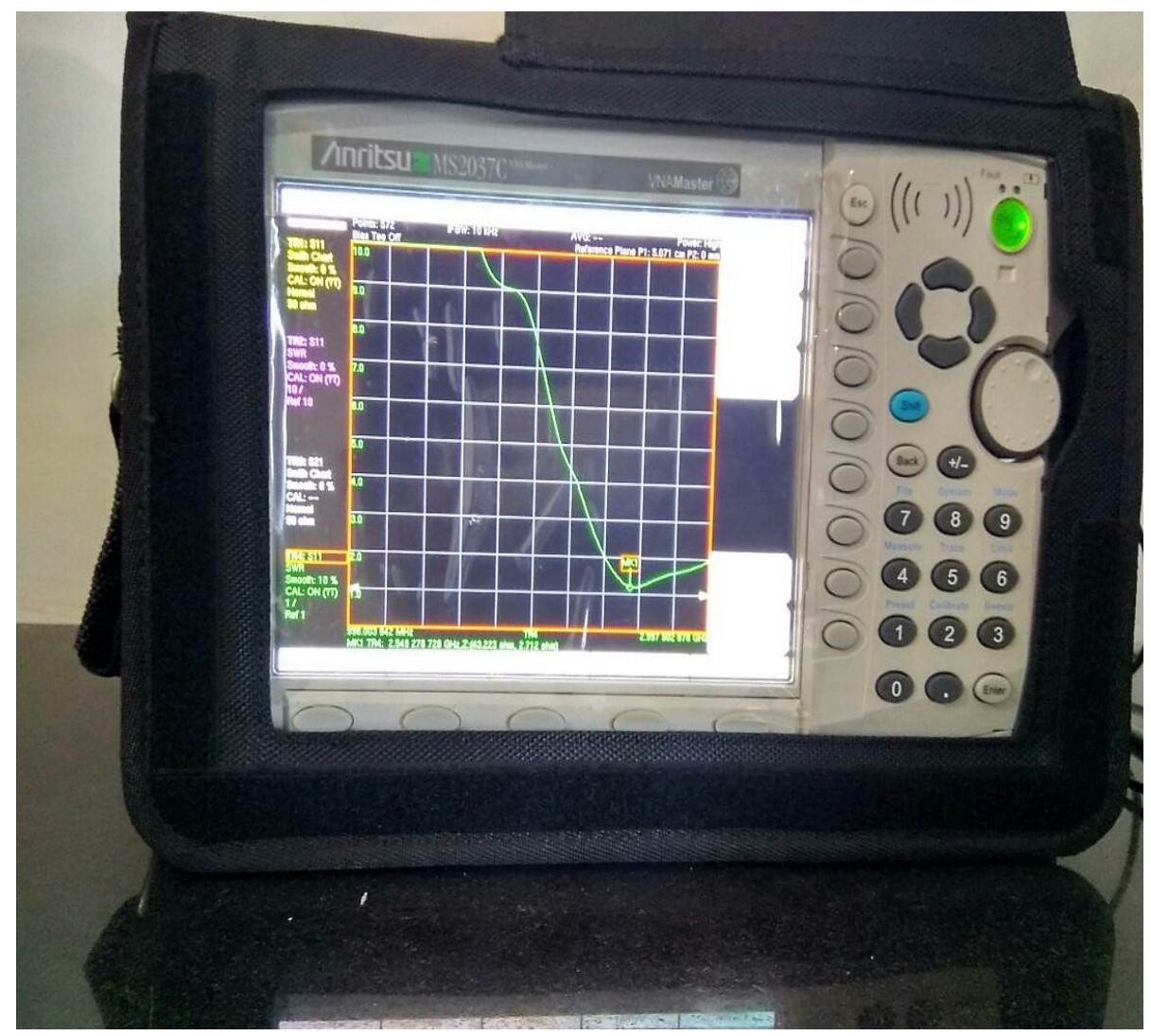

Fig. VSWR

The effectiveness of the designed solution is verified by series of tests which are devised to check the UHF RFID transponder operability, as well as the effectiveness of the selected harvested power source and supercapacitor storage device.

Series of tests concerning the charging time of the supercapacitor via the solar panel are also performed. To replicate different environments, the complete system is set up in different light intensities which are measured using the Lux meter. The full system is set and the voltage level of the supercapacitor is read at an interval of 1 second and stored on a computer. The first test carried out is in natural light with a light intensity of 15600 Lux and took $68 \mathrm{~min}$ to charge fully. The second used artificial office lighting of around 400 Lux and took 700 min to charge fully. Lastly, direct sunlight is used which has a Lux level in excess of the light meters maximum range which is in excess of 38000 Lux and only took 10min to charge fully.

The test which can verify the ability of the prototype to be operational throughout the night is also performed. To ensure the supercapacitor gives enough power to the chip when there is no sunlight a discharge test is carried out. This is essentially a full system test with the solar panel removed, and the voltage level of the supercapacitor is taken at regular time intervals via a multimeter and stored on the computer. The test confirms the prototype is able to be operational several hours without solar panel when fully charged.

\section{APPLICATIONS}

- People tracking: Hospitals and jails are most general tracking required places in order to look after special patients and to keep a close eye on jail inmates. 


\section{International Journal of Innovations in Engineering and Technology (IJIET) \\ http://dx.doi.org/10.21172/ijiet.83.022}

- Manufacturing: This process helps in better analysis, reduced time in locating parts and products and production process based sensors can be installed to alert any anomalies.

\section{CONCLUSION}

The papert describes a design of UHF RFID semi-active transponder with super capacitor. The proposed prototype is measured in order to determine the effectiveness the designed solution. The RFID transponder consists of the EM 4325 chip, On-Board dipole antenna, monocrystalline photovoltaic panel, and $10 \mathrm{~F}$ supercapacitor and protection circuit realized by the voltage regulator. Time needed to fully charge of the prototype for different light sources (20min for direct sunlight, $68 \mathrm{~min}$ for natural light and $700 \mathrm{~min}$ for artificial office lighting), operational time of the prototype without light source is more than $16 \mathrm{~h}$. The simulated antenna characteristics (i.e. return loss, VSWR) and the practical hardware results are in good agreement. Return loss showed a value of below 10(according to standards) and VSWR between 1 to 2 .

\section{REFERENCES}

[1]. VOJTECH, L., L. KYPUS, L. KVARDA, N. THIARD and J. YANNIS. Solar and Wireless Energy Harvesting Semi-active UHF RFID Tag Design and Prototyping. In: 16th International Conference on Mechatronics-Mechatronika 2014. Brno: IEEE, 2014, pp. 188-193. ISBN 97880-214-4816-2. DOI: 10.1109/MECHATRONIKA.2014.7018257.

[2]. Gary VALENTINE1, Lukas VOJTECH 2, Marek NERUDA21College of Engineering, Mathematics and Physical Sciences, University of Exeter, Prince of Wales Road, Exeter, Devon UK, EX4 4SB, United Kingdom 2Department Telecommunication Engineering, Faculty of Electrical Engineering, Czech Technical University in Prague, Technicka 2, 16627 Prague, Czech Republicgv221@exeter.ac.uk, lukas.vojtech@fel.cvut.cz, marek.neruda@ fel.cvut.cz DOI: 10.15598/aeee.v13i4.1485

[3]. SAMPLE, A. P., J. BRAUN, A. PARKS and J. R. SMITH. Photovoltaic Enhanced UHF RFID Tag Antennas for Dual Purpose Energy Harvesting. In: IEEE International Conference on RFID. Orlando: IEEE, 2015, pp. 146-153. ISBN 978-1- 4244-9607-5. DOI: 10.1109/RFID.2011.5764615.

[4]. HANDE, A., R. BRIDGELALL and B. ZOGHI. Vibration Energy Harvesting for Disaster Asset Monitoring Using Active RFID Tags. Proceedings of the IEEE. 2010, vol. 98, iss. 9, pp. 1620-1628. ISSN 0018-9219. DOI: 10.1109/JPROC.2010.2050670.

[5]. KAHROBAEE, S. and M. C. VURAN. Vibration energy harvesting for wireless underground sensor networks. In: IEEE International Conference on Communications (ICC). Budapest: IEEE, 2013, pp. 1543-1548. ISBN 978-1-4673-3122-7. DOI: 10.1109/ICC.2013.6654733.

[6]. VOJTECH, L., J. SKAPA, R. BORTEL, T. KORINEK and M. NERUDA. UHF RFID Tag Design for Disaster Management. In: 38th International Conference on Telecommunications and Signal Processing (TSP). Prague: IEEE, 2015, pp. 168-171. ISBN 978-1-47998498-5. DOI: $10.1109 /$ TSP.2015.7296245.

[7]. YEO, J., S.-G. MOON and J.-Y. JUNG. Design of antennas for a battery-assisted RFID tag with a thin and flexible film battery. In: IEEE Antennas and Propagation Society International Symposium. Honolulu: IEEE, 2007, pp. 5463-5466. ISBN 978-1-4244-0877-1. DOI: 10.1109/APS.2007.4396784.

[8]. ABDULHADI, E. and R. ABHARI. Multi-Port UHF RFID Tag Antenna for Enhanced Energy Harvesting of Self-Powered Wireless Sensors. IEEE Transactions on Industrial Informatics. 2015, vol. PP, iss. 99, pp. 1-8. ISSN 1551-3203. DOI: 10.1109/TII.2015.2470538 